\title{
Improvement of grain drying technology through the rapid grain heating and heat recuperation of wet gases
}

\section{Igor Gaponiuk}

\author{
National University of Food Technologies, Kyiv, Ukraine
}

Keywords:

Drying
Grain
Convection
Humidity
Porous

Article history:

Received 05.05.2017

Received in revised

form 30.06.2017

Accepted 05.09.2017

\section{Corresponding \\ author:}

Igor Gaponiuk

E-mail:

nuft2016@gmail.com

DOI:

$10.24263 / 2310-1008-$ 2017-5-1-7

\begin{abstract}
Introduction. The technology of drying the grain is a bottleneck in the technology of its storage. The modern dryings technology of the grain does not meet the requirements of productivity, energy intensity and quality of its drying.
\end{abstract}

Materials and methods. An object of researches is kinetics of temperature of layer of grain. Standard methods of research of the grain. Known methods for studying gas parameters and mathematical methods of research calculating the results.

Results and discussion. We have established the reasons for the growth of energy consumption for grain drying and influences. The main reason for growth of energy consumption consist in the increase in resistance to the intracapillary moisture diffusion in the grain body. The main growth factor of the resistance to the internal diffusion in the grain body is the imbalance of the intracapillary pressure in layers of the seed body. We have found the numerical dependence of the intracapillary resistance to moisture diffusion on the drying rate and body size of the seeds. Probably we are first who in the testing conditions developed and verified the method for reducing intracapillary resistance to diffusion. We have not still encountered such studies in publications that's why in article we gave calculations on the decrease in resistance of the intracapillary moisture diffusion for modes and design of American GH-2419 shaft dryer. The application of our method for reducing energy consumption of drying does not require essential changes in the design of the shaft dryer and will not lead to the decrease in the performance of this dryer. This article provides for the theoretical substantiation of the method for reduction of unit costs for grain drying heat via decrease in the resistance to internal moisture diffusion in the capillaries of the body of the seed.

The theoretical interest consists in our research of numerical dependence of the internal resistance to moisture diffusion in the capillaries of the seed body on drying rate and body size of the seed. The practical importance in studies set forth in the article can be perceived in the possibility to reduce the specific energy consumption in grain drying up to $25 \%$ through the improvement of drying technology and design of dryers. Both scientists and manufacturers of grain dryers may get interested in this article in order to improve their design.

Experimental studies have shown technological possibility and economic feasibility of the method for the grain pre-heating. The use of heat of exhaust drying gases for these needs will allow accelerating the drying of grains up to $25 \%$ and reducing energy consumption for drying up to $35 \%$. Our developed method does not require significant capital investments and may be applied to existing designs of domestic or foreign shaft grain drvers.

Conclusions. Experimentally proved the technological feasibility of using heat of the exhaust drying gas with the limited relative humidity $(\varphi, \approx 97$ to $99 \%$ ) for pre-heating of wet grain before its dehydration and tested technological method and modes in which the dehydrated grain is heated almost ten times faster and humidified only by $\delta W=0.3-1.7 \%$. 


\section{Introduction}

The indicators related to drying technologies, such as the grain drying speed, layer-bylayer uniformity of moisture content in a grain body and chemical changes in thermolabile components associated not only with the grain body temperature, as a whole, but with a nature of the grain layer heating, heat exchange method and temperature in seed body layers. Because the drying speed and drying uniformity are in power-law dependence on its temperature, thus, in practice a grain layer is sought to be heated as quickly as possible up to the threshold values. However, in terms of interphase heat-and-moisture exchange with heated working gases, at the initial drying stage not only the grain is not heated, but also it may be somewhat cooled down.

This is due to the priority use of the heat of working gases on phase transformations of moisture contained in the surface seed layers, and shortage of energy of these gases for further heating of the seed body. With the increase in moisture content and grain body size not only the duration of the heating is increased, but it concerns a layer-by-layer heterogeneity of moisture content and temperature in the seed body as well that leads to the microtrauma of the seed body, damage to chemical constituents and excess heat losses [1, $4,6,8]$. Based on the known drying technologies, the heating time of the grain layer of different sizes of the seed body and a moisture content may range from 10 to 15 till 90 to 120 minutes, and the grain microtrauma increases up to $25 \%$ and more $[3,7,9]$.

Substantiation of the idea. The relevance of the grain layer heating is supported by the direct dependence of the kinetics of its heating with the kinetics and energy consumption of dehydration $[5,6]$. This is due to the fact that the speed of internal and external moisture diffusion in the pores of the seed body is in the power-law dependence on the temperature of the seed body. And the intensity of grain drying, in turn, is directly related to the moisture diffusion rate in these pores. Therefore, at the initial drying stage the important thing is to rapidly heat a dehydrated body. To do this, it should create conditions of interphase heat exchange in which the greatest possible share of the heat of drying gases will be spent on the grain heating, and smaller one - on its dehydration. Such conditions are characterized by minimum values of the Kosovich criteria $(\mathrm{Ko} \rightarrow 0)$.

In our opinion, the most technically acceptable and cost-effective way of ensuring conditions of acquiring the $K o \rightarrow 0$ requirements for convective dryers is the use of exhaust working gases with an increased moisture content. In this case, the difference in the moisture content of phase environments (partial pressures) reaches minimum values and the heat of working gases will be to the maximum used for heating the seed body. That is, $K o \rightarrow 0$. However, to prevent or to reduce the risk of grain humidification due to the steam condensate of such gases, it is necessary to establish rational modes for the interphase interaction.

\section{Materials and methods}

An object of researches is kinetics of temperature of layer of grain.

Standard methods of research of the grain [7]. Known methods for studying gas parameters and mathematical methods of research calculating the results [6-9]. 


\section{Measuring devices}

Mass - by scales laboratory electronic ET-600P-E (Pat Bec) and scales electronic BTHE-6L1;

Temperatures of grain - by mercury thermometers, by thermocouples with the electronic transformer of TM-914C;

Temperatures of drying gases and air - by the thermoanemometer of TTM- 2 and by the portable measuring device of humidity and temperatures of gases of IBTM- 7;

Humidities of grain - by the expressanalyzer of Wil Digital, Grain MastureTester PM-400, and also in the drying closet of SESH-3;

Content of moisture of drying gases and air - by the portable measuring device of humidity, content of moisture and temperatures of gases of IBTM-7, by the psychrometer of PBU-1;

Speed of flow of drying gases and air, aerodynamic resistance and losses of pressure manovakometrom digital MMC-200 with tubes pressure, by the micromanometer of MMH200 , by the thermoanemometer of TTM-2;

Duration of experiment - by stop-watches.

\section{Methods of calculations}

Humidity of layer of a grain was set by expressanalyzers, standard and exemplary methods. A standard method is taken to drying of portions of the ground up grains in the drying closet of Sesh-1 at a temperature $130^{\circ} \mathrm{C}$ during 40 min with the further cooling.

A calculation to the coefficient was executed the to the exchange of moisture layer of grain and gases after a well-known formula [1-4]:

$$
\mathrm{g}_{\mathrm{m}}=\beta \cdot \rho_{\mathrm{o}}\left(\text { ип.к. }-\mathrm{u}_{\mathrm{p}}\right),
$$

where $g_{m}$ is intensity of evaporation of moisture from the surface of weevil in an environment, $\mathrm{kg} /\left(\mathrm{m}^{2} \cdot \mathrm{h}\right) ; \beta$ is a coefficient of to content of moisture; $\rho_{\mathrm{o}}$ is a closeness of dry substances of grain, $\mathrm{kg} / \mathrm{m}^{3} ; \mathrm{u}_{\mathrm{g}}$ - content of moisture on the surface of grain, that answers a critical point, $\mathrm{kg} / \mathrm{kg} \mathrm{d} . \mathrm{m} ; \mathrm{u}_{\mathrm{p}}$ - equilibrium content of moinsture, $\mathrm{kg} / \mathrm{kg}$ d.m.

The coefficient of to the exchange of moisture was expected after a well-known formula $[1,2,5]$ :

$$
\beta=\frac{N \cdot R \cdot p_{u} \cdot \phi}{100 \cdot\left(p_{s}-p_{n}\right) \cdot \omega_{p}},
$$

where $\mathrm{N}$ is speed of drying, of \%/min.; $\mathrm{R}$ - the brought radius over of grain, $\mathrm{m}$ (took from a table or accepted dекв $\approx 4 \cdot \mathrm{Rs}$ ).

The methods of calculations of experimental data executed in accordance with the chosen plan of experimental researches. The number of reiterations of experiments answered the criterion of logically-possible rejections and sufficientness for establishment of dependence.

The statistical estimation of the got results was carried out after the mean values of supervisions $\mathrm{y}_{\mathrm{u}}$. For the numeral estimation of coefficients in empiric dependences applied a least-squares method $[2,6-8]$. Essence of that is taken to the estimation of authenticity of the got results of researches thus. 


\section{Results and discussion}

Actual data of the exhaust drying gas indicators, obtained by us on the basis of the drying of different crops for different seasons of dryers`operation, allowed establishing the technological and economic feasibility of their use for pre-heating the grain layer. The temperature of these gases exceeds the temperature of the wet grain in summer period from 15 to $25^{\circ} \mathrm{C}$ and in winter from 30 to $45^{\circ} \mathrm{C}$.

The heat of the exhaust drying gases in terms of the steam contained in them can be calculated by the known formula of the difference in enthalpies of gases in the environment $\left(I_{0}\right)$ and exhaust ones $\left(I_{2}\right)$ :

$$
Q_{\text {grain heating }}=M \cdot\left(I_{2}-I_{0}\right) \text {, }
$$

where $I_{0}$ and $I_{2}$, respectively, the enthalpy of the air and the exhaust drying gas in moisture content of the air $d_{0}$ and gases $d_{l}, \mathrm{~kJ} / \mathrm{kg}$ dry air, $\mathrm{M}$ - losses of working gases for the grain drying, $\mathrm{kg} / \mathrm{h}$

By considering the ambient air and exhaust working gases as a mixture of gases and moisture steam contained in them, respectively, the enthalpy can be expressed in a similar and acceptable way for further calculations by using thermal characteristics of components of gases:

$$
Q_{\text {grain heating }}=M \cdot\left[c_{\text {dry air }} \cdot\left(t_{2}-t_{0}\right)+\lambda_{0} \cdot\left(d_{1}-d_{0}\right)+c_{s} \cdot\left(d_{1} \cdot t_{2}-d_{0} \cdot t_{0}\right)\right] \text {, }
$$

where: $t_{0}$ and $t_{2}$ - temperature of environment gases and exhaust drying gases, ${ }^{\circ} \mathrm{C} ; d_{0}$ and $d_{1}$ - moisture content of the ambient air and exhaust drying gases, $\mathrm{g} / \mathrm{kg}$ dry air; $c_{\text {dry air }}$ specific heat of dry air, $\mathrm{kJ} / \mathrm{kg}\left(c_{\text {dry air }}=1.004 \mathrm{~kJ} / \mathrm{kg}\right.$ dry air $) ; \lambda_{0}$ is heat of vaporization at temperature $t=0{ }^{\circ} \mathrm{C}\left(\lambda_{0}=2.500 \mathrm{~kJ} / \mathrm{kg}\right) ; c_{s .}$ - specific heat of superheated steam, $\mathrm{kJ} / \mathrm{kg}\left(c_{s}=\right.$ $1.842 \mathrm{~kJ} / \mathrm{kg}$ ).

Given the heat of gases of the air and moisture steam contained in the exhaust gases, the heat loss with these gases in recalculation to the drying of the planned one ton of grains for various drying conditions can be ranged from 130-240 MJ per 1 planned ton, or in recalculation to the heat generating capacity of natural gas is $4.2-7.8 \mathrm{~m}^{3}$ per 1 planned ton.

This heat may be enough to heat one ton of wet grain at $50-100{ }^{\circ} \mathrm{C}$. Taking into account the technical heat losses of the convective heat exchanger, we can assert that the heat from exhaust drying gases can reliably heat one ton of grains up to the limit temperature.

To clarify rational modes of convective grain heating by means of exhaust working gases in compliance with the $K o \rightarrow 0$ requirements and a minor risk of grain humidification, there were experimental investigations close to the manufacturing conditions in terms of the thickness of the grain layer with different designs of dryers $(h=0.22-0.31 \mathrm{~m})$ and parameters of the exhaust gases. The moisture content $\left(d_{1}\right)$ and relative humidity $\left(\varphi_{2}\right)$ of the exhaust drying gases in the experiments were by 20-30\% more than average production indicators of the shaft dryers. Such worse indicators of interphase moisture for grain heating were provided by us in order to create comparatively more risk for humidifying the grain with condensate of this gases from production ones.

Studies related to convective heat-and-moisture exchange of wet grain $\left(\theta_{0}, W_{0}\right)$ with the exhaust drying gases $\left(t_{2}, d_{l}\right)$ based on which $t_{2}>>\theta_{0}$ and $W_{0} \leq W_{\text {equilibrium }}$ it was established that by means of the provided heat of these gases $\left(Q_{2}\right)$ and variable speed of their flow $\left(v_{2}\right)$ 
one can control the moisture energy in the surface grain layer $\left(I_{s . l .}\right)$ and on the surface of the seed body $\left(I_{\text {s.s. }}\right)$ and, accordingly, the moisture gradient of phase environments.

It was experimentally proved that under conditions of significant temperature differences of phase environments $\left(\left(t_{2}-\theta_{0}\right)>>0\right)$, a little difference in the moisture content of these environmental $\left.\left(W_{r . h} \approx W_{0}\right)\right)$ and counter gradients of temperature and moisture, the direction of interphase moisture diffusion is more significantly affected by the energy status of the moisture in surface layers of the grain body [6]. This can be explained by the fact that already at the initial stage of phase-to-phase interaction the layer temperature of the grain rapidly grows and, accordingly, increases the energy state of moisture in the surface layers of the seed body. In its turn, this leads to the increase of propulsive potential for grain dehydration. In our opinion, this additional potential for grain dehydration, most likely, hinders its humidification by wet gases under conditions of excess in equally weighted moisture over the grain humidification.

The heating rate of barley grain layer with thickness $\mathrm{h}=0.25 \mathrm{~m}$ by using gases with the increased moisture content $\left(d_{0}=20-21 \mathrm{~g} / \mathrm{kg}\right.$ dry air $)$ was increased by 8 to 11 times compared to the dry gases $\left(d_{0}=6-10 \mathrm{~g} / \mathrm{kg}_{\text {dry air }}\right)$ with the same temperature $\left(t_{2}=22-28{ }^{\circ} \mathrm{C}\right)$, and amounted to $d \theta / d \tau=4.5-6.5\left({ }^{\circ} \mathrm{C} / \mathrm{min}\right)$. Larger values of the grain heating speed were consistent with larger temperature difference between phase environments $\left(t_{2}-\theta_{0}\right)$ and higher gas flow speed $v_{2}$.

To prevent pyrocondensation on the surface of remote grain layers, we increased the flow rate of gases with increased moisture content $\left(v_{2}\right)$ from 0.2 to $2.7 \mathrm{~m} / \mathrm{s}$ and changed the pressure gradient of gases $( \pm \mathrm{H})$.

The value of the actual grain moisture $\left(W_{i}\right)$ during its heating in the heat-exchange chamber was defined on the basis of the condensate value $\delta W_{w . v}\left(W_{i}=\mathrm{W}_{0}+\delta \mathrm{W}_{\mathrm{w.v}}\right)$ and compared with those obtained in a standard way in the drying box. The condensate value $\delta M_{w . v}$ was established by the product of the difference in moisture content of gases before and after the grain layer $\left(d_{t}, d_{2}\right)$ on the consumption of working gases $L$ :

$$
\delta M_{\text {condensate }}=L \cdot\left(d_{t}-d_{2}\right) / 1000,
$$

The current temperature of the grain layer was detected on the basis of indicators of temperature sensors placed in the grain layer.

Figure 1 shows the temperature dynamics for barley grain with different moisture contents $\left(W_{0}=13-25 \%\right)$ when heating it with warm gases of high humidity $\left(t_{2}=26-28{ }^{\circ} \mathrm{C}\right.$, $\left.\varphi_{2} \approx 97-99 \%, \mathrm{~d}_{1}=20-21 \mathrm{~g} / \mathrm{m}^{3}\right)$.

The temperature kinetics for control sample of barley grain with moisture content $\mathrm{W}_{0}=$ $25 \%$, and initial temperature $\theta_{0}=12{ }^{\circ} \mathrm{C}$ for the heating operation with dry gases $\left(d_{0}=6-10\right.$ $\left.\mathrm{g} / \mathrm{kg}_{\text {dry air }}\right)$ at the same temperature $\left(t_{2}=26-28{ }^{\circ} \mathrm{C}\right)$ are shown with the graphical dependence 5 in Figure 1.

Figure 2 shows the moisture kinetics for the wheat grain layer when heating the same gases. The obtained values of the calculated and actual moisture contents of the wheat grain allowed confirming the possibility of reducing the moisture of the grain layer by $2-6 \%$ in comparison with the calculated data established by heat exchange modes.

It was experimentally proved that with the increase of the temperature difference of the phase environments, the actual increase of grain moisture content is reduced based on the results of its humidification of gas condensate (graph $b$, Figure 2) compared to the calculated (graph $a$ ) Figure2). The estimated increase in the grain moisture, the initial temperature $\theta=6^{\circ} \mathrm{C}$ (graphical dependence 1a, Figure2) is $\Delta W=1.9 \%$. 


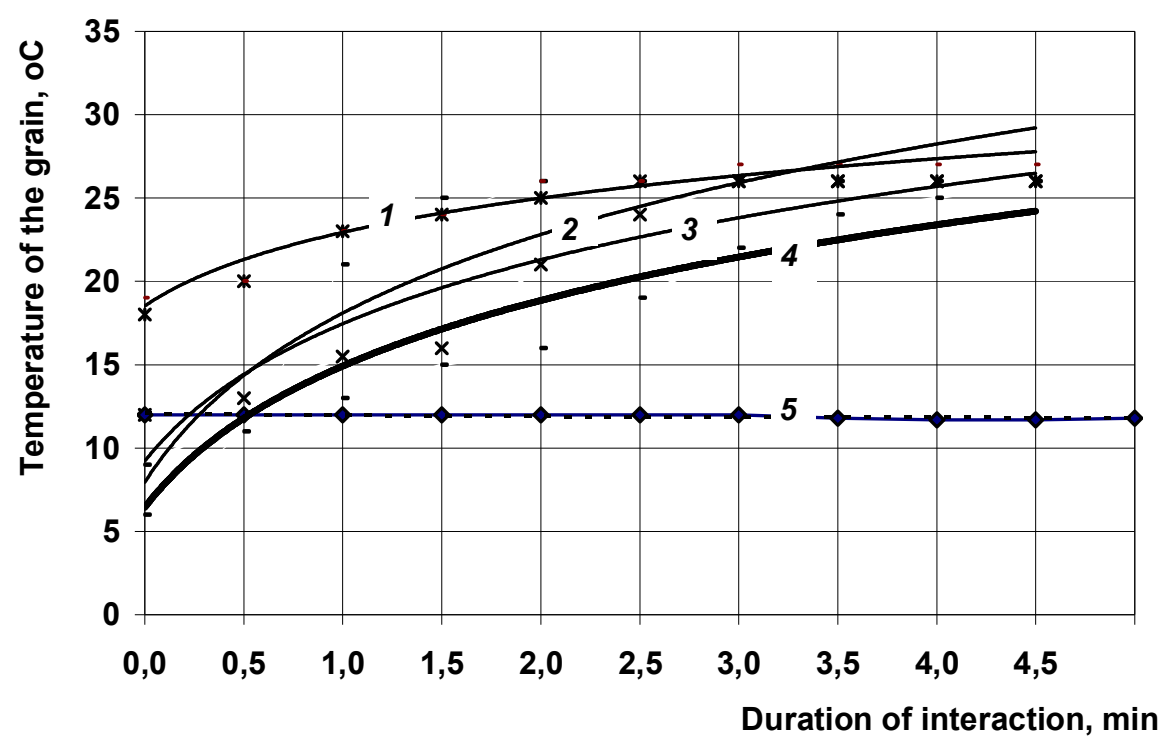

Figure 1. Dynamics of barley grain temperature with different moisture contents $\left(\mathrm{W}_{0}\right)$ and temperature $\left(\theta_{0}\right)$ :

$1-W_{0}=25 \%, \theta_{0}=19{ }^{\circ} \mathrm{C} ; 2-W_{0}=20 \%, \theta_{0}=12{ }^{\circ} \mathrm{C} ; 3-W_{0}=25 \%, \theta_{0}=9{ }^{\circ} \mathrm{C} ;-W_{0}=13 \%$, $\boldsymbol{\theta}_{0}=9{ }^{\circ} \mathrm{C} ; 3-W_{0}=21 \%, \boldsymbol{\theta}_{0}=12{ }^{\circ} \mathrm{C}$.

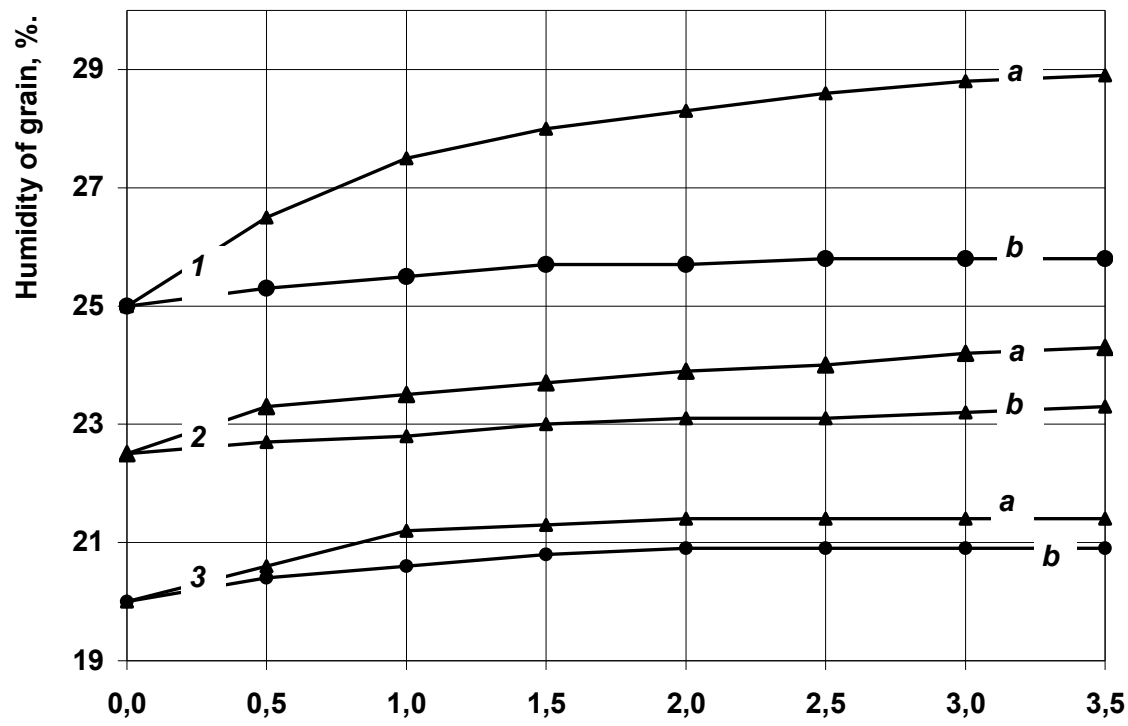

Duration of the phase-to-phase interaction, min.

Figure 2. Dynamics of wheat grain moisture contents of calculated (a) and actual (b): $1-\theta=6^{\circ} \mathrm{C}, \mathrm{W}=20 \% ; 2-\theta=10{ }^{\circ} \mathrm{C}, \mathrm{W}=22.5 \% ; 3-\theta=11{ }^{\circ} \mathrm{C}, \mathrm{W}=25 \%$. 
However, the actual one, pursuant to established supply modes of exhaust drying gas, is only $\Delta W=0.2 \%$. With increasing initial grain temperature $\theta=11{ }^{\circ} \mathrm{C}$ and humidity $W_{0}=25 \%$ (graphical dependence $3 \mathrm{a}$ and $3 \mathrm{~b}$ in Figure2) the risk of grain humidification is significantly reduced when it is heated by exhaust drying gases.

Experiments established that in addition to the difference of temperatures of phase environments $\left(\theta_{0}-t_{2}\right)$ the condensate hydration of these gases is significantly affected by the penetration speed of the grain layer. Therefore, with the increase of the flow rate of wet gases the probability of grain humidification by the condensate of these gases decreases.

Below you can find calculations of the economic feasibility for the method on heating of the wet grain of the exhaust drying gases. For summer period of dryers' operation such exhaust gas parameters are as follows: temperature $t_{2} \leq 50{ }^{\circ} \mathrm{C}$, humidity of upper drying zones $\varphi_{2} \approx 90 \%$ and $\varphi_{2} \approx 55 \%$ for lower ones [4]. Taking into account the design features of shaft dryers and gas pipelines from supply of exhaust gases for re-use of their heat, heat loss through the heating surfaces of pipelines and heat exchange chamber can reach 7\% [ 3 ] to $15 \%[1,2,4]$.

The temperature of the grain harvested during the day can vary in a wide range $\theta_{0}=5$ $20{ }^{\circ} \mathrm{C}$ and humidity $W_{0}=15-30 \%$.

It is obvious that while heating a wet grain by exhaust gases, its temperature cannot exceed the temperature of the coolant $\left(\theta_{1} \leq \mathrm{t}_{2}, \theta_{1} \approx 28^{\circ} \mathrm{C}\right)$ and grain moisture for the worst conditions of phase-to-phase interaction can be moistened at $\delta W=0.5-1.5 \%$.

Heat losses $Q_{\delta \theta}$ for heating the grain up to the temperature of the exhaust gases can be calculated by using the known formula [1,2]:

$$
Q_{\delta \theta}=G \cdot c_{0} \cdot\left(\theta_{1}-\theta_{0}\right),
$$

where $G$ - grain mass, $\mathrm{kg} ; c_{0}$ - specific heat of grain with humidity $W_{0}, \mathrm{~kJ} /(\mathrm{kg} \cdot \mathrm{K}) ; \theta_{0}$ and $\theta_{I}$ - final and initial grain temperature, ${ }^{\circ} \mathrm{C}$.

Heat losses of dehydration of extra grain moisture (condensate), which can penetrate into it from the exhaust gases, can be calculated by the known formula [1,2]:

$$
Q_{\delta W}=G \cdot \delta W \cdot(r+\Delta r),
$$

where $\mathrm{r}$ is the latent heat of vaporization at the grain temperature $\theta_{l}, \mathrm{~kJ} / \mathrm{kg}_{\text {humid. }} ; \Delta r-$ specific heat for overcoming the internal resistance to moisture diffusion, $\mathrm{kJ} / \mathrm{kg}_{\text {humid }}, \delta W-$ value of moisture condensation on the grain surface, $\mathrm{kg}$.

According to the performed estimates of the method of wheat grain heating with relative humidity $W_{0}=17.5-20 \%$ and temperature $\theta_{0}=16-17{ }^{\circ} \mathrm{C}$ by exhaust drying gases with moisture content $20.5-22.5 \mathrm{~g} / \mathrm{m}^{3}$ and $t_{2}=28^{\circ} \mathrm{C}$, heat savings may be: $\delta Q=Q_{\delta \theta}-Q_{\delta W}=$ 13 to $20\left(\mathrm{~kJ} / \mathrm{kg}_{\text {grain }}\right)$.

$$
\delta Q=Q_{\delta \theta}-Q_{\delta W}=13 \text { to } 20\left(\mathrm{~kJ} / \mathrm{kg}_{\text {grain }}\right) .
$$

Or in recalculation to the natural gas for heating one ton of grains -0.45 to $0.66 \mathrm{~m}^{3} / \mathrm{t}$.

In addition, it should note the following technological advantages of pre-heating by such method as ten-fold increase in the heating speed of the wet grain layer before its dehydration. This will allow not only to accelerate intracapillary moisture diffusion and to level a layer-by-layer heterogeneity of moisture content in the grain body, but also to reduce the risk of the layer-by-layer overheating of thermolabile components in the seed. 
The given calculations in the experimental studies provide that under these conditions a phase-to-phase interaction (flow rate of working gases, state of the mobility of the grain layer and difference between gas temperature $t_{2}$ and grain temperature $\theta_{0}$ ) the grain layer is heated ten times faster than conventional methods for heating the grain via dry gases.

\section{Conclusions}

1. The largest share of heat losses of modern technologies for grain drying applies to the exhaust drying gases. In a majority of domestic dryers, the losses are $35-45 \%$ of the total heat losses and for foreign ones $-25-40 \%$;

2. The temperature of the exhaust drying gases exceeds the grain temperature in summer by $15-25^{\circ} \mathrm{C}$ and in winter by $3-45^{\circ} \mathrm{C}$, absolute humidity is $21-23 \mathrm{~g} / \mathrm{kg}_{\text {dry }}$ air. The heat of these gases can heat almost twice more grain supplied to the grain dryer;

3. The heating rate of wet grain via exhaust drying gases is ten times more than heating rate of dry gases and duration of its heating up to the temperature of these gases is $2-5$ $\min$;

4. The specified phase-to-phase modes of interaction (speed of their flow, mobility state of the grain layer and method of supplying gases) can significantly reduce the risk of condensation of the condensed moisture on the grain layer surface;

5. We experimentally proved the technological feasibility of using heat of the exhaust drying gas with the limited relative humidity $\left(\varphi_{2} \approx 97-99 \%\right)$ for pre-heating of wet grain before its dehydration and tested technological method and modes in which the dehydrated grain is heated almost ten times faster and humidified only by $\delta W=0.3-1.7$ $\%$.

6. Based on actual indicators of working gases of shaft dryers $\left(\varphi_{2}=45-75 \%\right)$, the risk of grain humidification in the process of heating such gases will be even less.

7. Re-use of heat by exhaust drying gases for heating the grain before its dehydration can reduce at $0.45-0.66 \mathrm{~m}^{3} / \mathrm{t}$ the unit costs of drying in recalculation to the natural gas.

\section{References}

1. Flaumenbaum B.L., Tanchev S.S., Grishin M.A. (1986), Osnovy konservirovaniya pishchevykh produktov [Fundamentals of food preservation], Moscow.

2. Ostapchuk M.V. (), Naukovi osnovy protsesiv zberigannya zerna [Scientific basis for grain storage processes], Scientific works of Odessa National Academy of Food Technologies, 29(2), pp. 58--62.

3. Gaponyuk I. (2013), Vplyv parametriv dovkillya na sushinnya zerna [The influence of environmental parameters on grain drying], Ukrainian Food Journal, 2(3), pp. 337346.

4. Gaponyuk I. I. (2014), Vitchyznyani zernosusharky: stan ta perspektyvy [Domestic grain dryers: status and prospects], Khranenie i pererabotka zerna [Storage and processing of grain], 2(179), pp. 25-29.

5. Chuanping Liu (2012), Size distribution in gas vibration bed and its application on grain drying, Powder Technology, 221, pp. 192-198.

6. Magdalena Zielinska (2012), Superheated steam drying characteristic and moisture diffusivity of distillers' wet grains and condensed distillers' solubles, Journal of Food Engineering, 109(3), pp. 627-634. 
7. Burova N. (2017), Wheat sprout grain drying in vacuum drying plants, 38(52).

8. Santos J.P. (2015), Wheat convective drying: An analytical investigation via Galerkinbased integral method, Defect and Diffusion Forum, 365, pp. 82-87.

9. (2014), 10th International Conference on Diffusion in Solids and Liquids, Mass Transfer - Heat Transfer - Microstructure and Properties - Nanodiffusion and Nanostructured Materials, Paris; France; 23-27 June 2014; Code 136759.

10. Smaniotto T. (2017), Drying kinetics of sunflower grains, 21(3), pp. 203-208. 